\title{
Research in general practice: law of inverse opportunity
}

\author{
Denis Pereira Gray
}

"Building Your Own Future: an Agenda for General Practice" is a strategy document currently being sent by the General Medical Services Committee to all general practitioners in Britain. It raises a series of questions about what general practice should be and how it should be organised and funded, and the committee wants the issues debated as widely as possible.

We have commissioned seven articles to contribute to that debate. We start this week with Denis Pereira Gray's argument for much more research in general practice-a subject only lightly addressed in "Building Your Own Future."

Only two groups of doctors in the British health service hold unsupervised responsibility for patients: consultants and general practitioner principals. There are about twice as many general practitioners as there are consultants in all specialties combined, ${ }^{1}$ making general practice the largest branch of the medical profession. The government noted that $90 \%$ of all the contacts between the population and the health service take place in primary care-a massive 225 million consultations in $1986 .^{2}$

General practitioners see almost all problems first and deal with about $90 \%$ of them with their colleagues in the primary health care team without reference to hospital. They manage about $90 \%$ of all patients with asthma; depression; hyperlipidaemia; hypertension; hypothyroidism; acute emotional problems; and infections of the ears, throat, lungs, bowel, skin, vagina, and urinary tract. Around $95 \%$ of people aged over 75 are in the care of a general practitioner. General practice is the only specialty in which doctors work regularly in the patients' own environment (the home), ${ }^{3}$ work frequently with several members of the family, and use therapeutically doctor-patient relationships built up over decades. ${ }^{4}$

General practice is the one part of the health service in which patients personally choose and change their doctor, and it is also the best place to study the balance of seriousness of health problems.

The government has decided that health promotion should be a main priority for the NHS. The need to integrate personal preventive medicine with therapeutic services should therefore put general practice centre stage as general practice is where most people get most care for most of the time and is the only place where the whole person can be studied medically by generalists in his or her natural habitat. As the health service is publicly committed to applying resources on the basis of need, research from general practice has a strong claim for a high priority. All efficient organisations devote a reasonable share of their resources to research and development. This ought also to be true for such a diverse service as general practice, which costs, including drugs, $£ 4.5$ billion a year (Department of Health, personal communication).

The recent appointment of Professor M J Peckham as the first director of research and development for the NHS makes this a logical time to review research supported by the NHS and to plan a research strategy and the place of educational opportunities for general practice within it. The new director is quoted as supporting $1 \cdot 5 \%$ of turnover as a target for research expenditure. ${ }^{5}$

Because standards of care in general practice are the most variable,${ }^{6}$ this is the setting where research is likely to be most cost effective in identifying ways of improving care for the maximum number of people for any given resource. The evidence is, however, that far from applying resources to where the needs are greatest, the current national system operates against general practice. Twenty years ago Hart described his "inverse care law." Now, another inverse law is operatingnamely, that educational opportunities for research training are available least to the branch of the medical profession which needs them most. Why is this so?

\section{History of general practitioner research}

The tradition of research in general practice is not well known. Yet Jenner, a general practitioner in the eighteenth century, carried out experiments that were to lead to the eradication of smallpox,${ }^{8}$ and in the nineteenth century Finlay, another general practitioner, made the crucial observation that yellow fever was transmitted by a mosquito and so opened up new approaches to prevention and cure. ${ }^{9}$ At the end of the century Mackenzie, in a working class general practice in Burnley, invented the polygraph, forerunner of the electrocardiograph, and did world class research on the heart. ${ }^{10}$

In this century Pickles defined the spread of infection for Bornholm disease and infectious hepatitis. More recently the Manchester research unit of the Royal College of General Practitioners has conducted one of the biggest prospective studies of the effect of the contraceptive pill ${ }^{12}$ and Huygen has shown the relation between illness in one family member and illness in another. ${ }^{4} \mathrm{~A}$ research thesis from the department of general practice at Nijmegen reporting lung function in people with asthma was one of the first reports that $\beta$ agonists were potentially harmful. ${ }^{13}$

\section{Content of research}

The challenge must be for general practitioners to define their topic of research. Firstly, must come the origins of disease, especially environmental factors; secondly, the prevention and management of disease in the home and family; and, thirdly, doctors must learn much more about how illness presents, what the first symptoms and signs actually are, and how general practitioners, "the front line of the health service," can make the earliest possible diagnoses and most appropriate interventions.

Perhaps a third of all ill health presented to general practitioners has an important psychological component. What is the relation between body and mind and how can optimal care be provided? How are we to understand and provide better care for the many people with so called psychosomatic disease, especially those patients who present with conditions they believe represent physical ill health ${ }^{15} 16$

Many of the major problems of our society such as truancy, interpersonal violence, substance misuse, and 


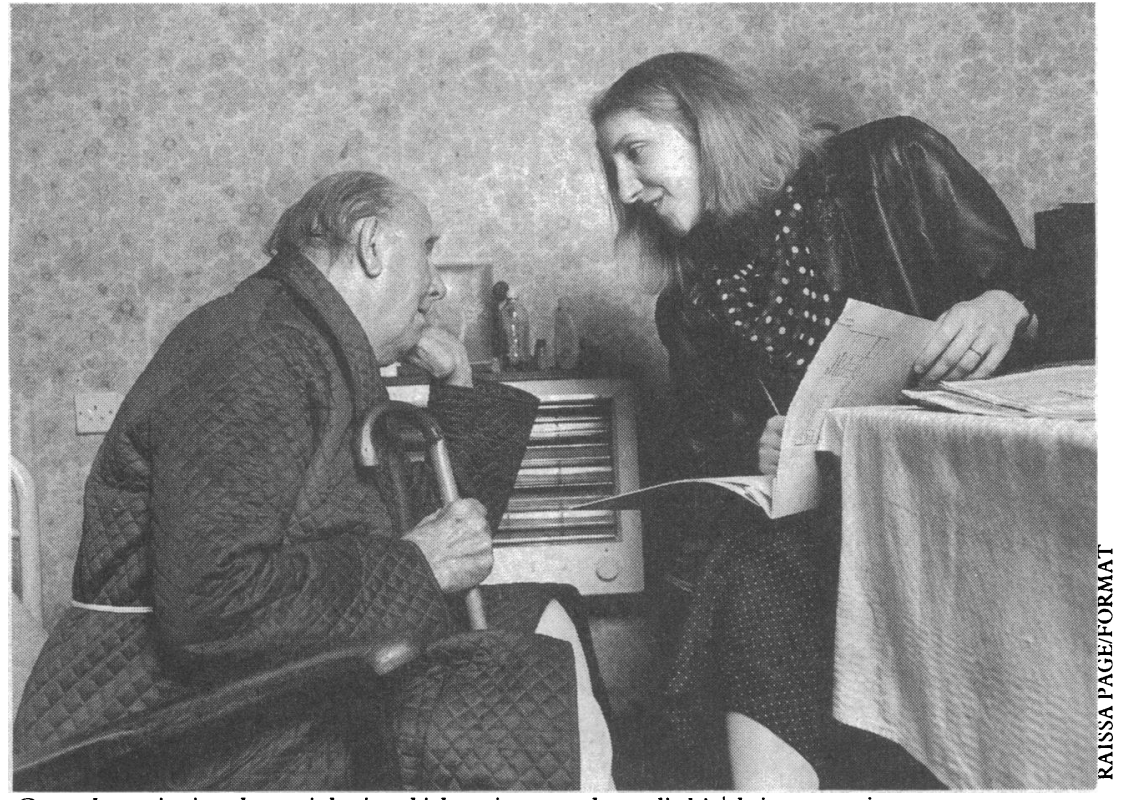

General practice is only specialty in which patients can be studied in'their own environment

above all the ability to sustain satisfactory human relationships could probably be altered for the better as a result of better understanding by the doctors, who are often in touch with families for years. Family factors in medicine are the most important and unstudied aspect of medical care.

Finally operational research questions need to be considered. General practitioners care for large numbers of patients. What is the most efficient way of caring for 461 patients aged over 75 in a medium sized practice such as my own, which also has 507 patients with asthma, 371 with hypercholesterolaemia, and 350 with hypertension. If physiotherapists attached to general practices can save many outpatient referrals to consultant orthopaedic surgeons and achieve quicker and cheaper care with equal or better outcomes (A Walker, personal communication) why is there not more finance for operational research?

\section{Vocational training}

Vocational training for general practice is unique in that it provides only a year's training in the doctor's chosen discipline. No physician or surgeon could even contemplate a career in their chosen specialty with only a year's experience. Furthermore as the 52 weeks are always reduced by five weeks' holiday and often by a week or two of sick leave, the time actually available to learn the discipline of general practice can amount to only 45 weeks.

In this time only the range of tasks; the major difficulties; and the orientation to people, homes, and families can be learnt. Serious theory and research inevitably have to wait, and for many they wait for ever.

\section{After vocational training}

Research opportunities can only be taken by the prepared mind and most research opportunities in general practice go by default. Some are lost because the general practitioner is already engaged up to the limits of his or her time, but many are lost because the practitioner is not equipped with the research skills to respond to a good idea or an interesting observation.

General practice vocational training schemes now often attract young doctors of great ability, many of whom have won prizes in their medical school. Several would like to go on to further education after completing their training, especially in research methodo- logy, but professors of general practice and regional advisers do not have a single post to offer. Their colleagues in specialist medicine, however, have the fast stream at the Hammersmith, or various "marked" hospital junior posts that can accelerate a career for enthusiasts in specialist medicine.

The absence of any educational opportunities after vocational training cripples the creation of enthusiastic and competent general practitioner researchers. It is both ironic and perverse that the health service will pay for an additional six months' vocational training if an approved trainer certifies that the trainee is not eligible for a statement of satisfactory completion of training but it will not pay if a trainee desires further training in research even if an academic department of general practice certifies exceptional ability.

\section{Specialist training}

The contrast between the educational opportunities available to doctors in specialist and generalist medicine is remarkable. Every one of the 3430 senior registrars in the hospital and public health branches of the medical profession ${ }^{1}$ is provided with a day a week funded by the NHS to acquire training in research methods appropriate to their specialty and often support in acquiring a higher university degree. The funding is equivalent to about 600 whole time research posts, and this support is available to every branch of medicine except the biggest.

What are needed first, as the Royal College of General Practitioners has proposed, ${ }^{17}$ are 12 training posts, perhaps some half time and some full time, in each health service region. These should be in open competition and perhaps linked to an academic department of general practice. In addition there should be formal recognition of at least 12 research general practices in each region, appointed on the basis of the quality of their previous research work and organisation.

The Department of Health has recently introduced funding separate from the service increment for teaching (SIFT) for non-teaching hospitals undertaking a large amount of research. As yet there is no general practice equivalent, although this could greatly help in establishing research general practices similar to teaching practices.

The extent of educational deprivation in general practice can be quantified. Williams has recently shown that on average only three of 30000 general practitioners in Britain gain an MD each year. ${ }^{18}$ This is the lowest ratio in all the medical specialties and numbers are falling.

\section{POSTDOCTORAL FELLOWSHIPS}

The effect of the lack of research can be seen in relation to postdoctoral research fellowships, which are an important way of developing a career in research. Many fellowships are advertised each year, especially by the Medical Research Council and several charities. Appointments are on merit, but effectively general practice is excluded as it is rare for general practitioners to obtain a doctorate.

\section{ACADEMIC POSTS}

The share of general practice academic posts in British universities is tiny. In 1988 only 391 (of which 234 were honorary) out of 6551 (2445 honorary) medical academic posts were in general practice-less than $6 \% .^{19}$ Thus there were only 157 paid posts for 25322 unrestricted general practitioner principals in the NHS in England or one post per 161 general practitioners, ${ }^{20}$ whereas for specialist medicine the ratio was 0.43 academic posts per consultant.

Furthermore many regional health authorities fund 
numerous full time or part time academic specialist posts in medical schools. There are a few general practice posts funded regionally, but they are rare. "The largest branch of the profession should be provided with a critical mass of university staff in the same proportion as is usual in other clinical disciplines."

\section{POSTGRADUATE INSTITUTES AND SPECIAL HEALTH} AUTHORITIES

Specialist medicine has gained greatly from about a dozen specialist institutes, which are powerhouses for research in their fields. They are supported by millions of pounds of public money through various mechanisms, including special health authorities (that is, NHS support) and through universities (for example, the British Postgraduate Medical Federation and University of London).

In 1987 there were over 100 professors in the postgraduate institutes of the British Postgraduate Medical Federation alone, but there was only one professor of general practice in a postgraduate department in Britain. ${ }^{14}$ In 1988 there were 578 medical consultants, 285 medical senior registrars, and 295 medical registrars working in seven medical special health authorities most with research time, but not one general practitioner. ${ }^{21}$ Some new mechanism or some adaptation of an existing mechanism is needed to allow general practice to develop an equivalent postgraduate academic institution.

\section{Remuneration}

Finally, the remuneration of both full time and part time staff of universities and medical schools is different for generalists and specialists, so that all research workers who are generalists are excluded from consideration for distinction awards. ${ }^{22}$ Distinction awards are held by about a third of all consultants at any one time and are received by more than half during a career. ${ }^{23}$ The result is that the best academics from general practice are paid almost exactly half what they would earn in any other branch of the profession.

In 1990 the dean of one London medical school considered that his professor of general practice was internationally distinguished and was being excluded from the awards scheme. He was rejected not because of merit but solely because this professor worked clinically in general practice. The chairman of the Conference of the Medical Royal Colleges and Faculties formally wrote to the Secretary of State for Health asking for equitable treatment for generalists without result (D Williams, personal communication). If the NHS Management Executive is serious about "integrating primary and secondary health care," anomalies like this will need to be reformed.

\section{Conclusion}

This is a logical time to reform the arrangements for training for general practice research. The recent appointment of a director of research and development in the NHS is welcome. Unless the opportunity for general practitioners to acquire research skills and the support for research practices and research posts in general practice are increased much valuable information will be lost.

Medical Manpower and Education Division, Department of Health. Medical and dental staffing prospects in the NHS in England and Wales 1989. Health Trends 1990:22:96-103.

2 Secretaries of State for Social Services, Wales, Northern Ireland, and Scotland. Primary health cure. An agenda for discussion. London: HMSO, 1986:34. (Cmnd 9771.)

3 Pereira Gray DJ. Feeling at home. $\mathcal{F}$ R Coll Gen Pract 1978;28:6-16.

4 Huygen FJA. Family medicine. The medical life history of families. London: Royal College of General Practitioners, 1990.

5 Smith R. Strangling the future. BMF 1991;302:977-8.

6 Irvine D. Quality of care in general practice: our outstanding problem. $\mathcal{F} R$ Coll Gen Pract 1983;33:521-3.

7 Hart JT. The inverse care law. Lancet 1971;i:405-12.

8 Louden I. Medical care and the general practitioner 1750-1850. Oxford: Clarendon Press, 1986

9 Porterfield JS. Yellow fever in west Africa: a retrospective glance. $B M \mathcal{f}$ 1989:299:155-7.

10 Mair A. Sir fames Mackenzie MD 1853-1925. General practitioner. London: Roval College of General Practitioners, 1986

11 Pickles WN. Epidemiology in country practice. London: Royal College of General Practitioners, 1984.

2 Royal College of Gencral Practitioners. Oral contraceptives and health. London: Pitman Medical, 1974.

13 Van Schayck CP. Treatment of asthma and chronic bronchitis in patients from general practice [PhD thesis]. Nijmegen: University of Nijmegen, 1990

14 Royal College of General Practitioners. The front line of the health service. Report from general practitioners. London: RCGP, 1987.

15 Grol R. To heal or to harm. The prevention of somatic fixation in general practice. London: Royal College of General Practitioners, 1988.

16 Wright AF. A study of the presentation of somatic symptoms in general practice by patients with psychiatric disturbance. $\mathrm{Br} \mathcal{F}$ Gen Pract 1990;40: $459-63$.

17 Roval College of General Practitioners. An academic plan for general practice. London: RCGP; 1990: 19. (Occasional paper 49.)

18 Williams WO. A survey of doctorates by thesis among general practitioners in the British Isles from 1973 to 1988. Br f Gen Pract 1990;40:491-4.

19 Department of Health. Medically qualified staff of universities, medical schools Department of Health. Medically qualified staff of universities, medical schools
and institutes - England and Wales, 30 September 1988. London: $\mathrm{DoH}, 1989$. (Table I.)

20 Department of Health. Health and social services statistics for England. London: HMSO, 1990

21 Department of Health. Hospital medical staff-England and Wales. Regional tables. Special health authorities (LPGTHs), 30 September 1988. London: DoH, 1989. (Table I.)

22 Edwards B, Pennington GW. Distinction and meritorious service awards for hospital doctors and dentists in the NHS. Keele: Health Services Manpower Review, 1987

23 Advisory Committee on Distinction Awards. Distinction awards: analysis by type of award, specialty, and percentage distribution at 31 December 1988 England and Wales. Health Trends 1989;21:137.

24 NHS Management Executive. Integrating primary and secondary health care. London: NHSME, 1991.

\section{A PAPER THAT CHANGED MY PRACTICE}

\section{Battered babies}

The sudden overwhelming revelation is not my style, but if I am asked "What paper published since you qualified in medicine has most affected the practice of paediatrics, and therefore your own practice?" the one that comes first to my mind was in the Fournal of the American Medical Association on 7 July 1962 . When I was a medical student the thought that parents might deliberately injure their own children never entered my head. Then along came Henry Kempe; suddenly the world was different and the practice of paediatrics had changed.

The title was deliberately provocative, intended to shock the profession into belief and action. The expressions "battered baby" and "battered child" travelled quickly. Looking at the paper again after nearly 30 years it is impressive how the essential clinical, radiological, psychological, and social features of nonaccidental injury are explained in eight pages. It was a

paper with a message which was clearly and unequivocally stated and which was received and acted on by the profession. Kempe and his colleagues in Denver recognised the difficulty that doctors had in coming to terms with the problem - "Many physicians find it hard to believe such an attack could have occurred, and they attempt to obliterate such suspicions from their minds, even in the face of obvious circumstantial evidence." We all learnt and are still learning, but there can be no doubt that over the past 30 years children have been protected as a direct result of this paper. It is not exaggeration to claim that on 7 July 1962 paediatrics lost the innocence of youth and entered a less attractive but more realistic adulthood. -DOUGLAS ADDY, consultant paediatrician, Dudley Road Hospital, Birmingham

Kempe CH, Silverman FN, Steele BF, Droegemueller W, Silver K. The battered-child syndrome. FAMA 1962;181:17-24. 